\title{
GENITAL MOLLUSCUM CONTAGIOSUM AND HIV- A COMPARATIVE STUDY
}

\author{
Dhumale Shashikant Balkrishna1, Phulari Yoganand J2, Bhanushali Sweta Pratap ${ }^{3}$
}

${ }_{1}^{1}$ Associate Professor, Department of Dermatology, D. Y. Patil Medical College, Kolhapur, Maharashtra.

${ }^{2}$ Assistant Professor, Department of Dermatology, D. Y. Patil Medical College, Kolhapur, Maharashtra.

${ }^{3}$ Resident, Department of Dermatology, D. Y. Patil Medical College, Kolhapur, Maharashtra.

\section{ABSTRACT}

\section{BACKGROUND}

Genital Molluscum (GM) is Sexually Transmitted Disease (STD), common in young adults. Will there be any clinical differences including dissemination with HIV status? So, we compared GM clinically in HIV positive and negative patients.

\section{MATERIALS AND METHODS}

50 patients of GM, 25 in each group of HIV positive and negative were compared in this observational and prospective study. P value less than i.e. $<0.05$ was considered as significant association.

\section{RESULTS}

A: HIV positivity was associated significantly in- a) Age: Higher age group (43 years and 28 years respectively) (p- 0.000); b) Trunk (p- 0.006); c) Face (p- 0.001); d) Giant size (p- 0.014); e) Infection or ulceration (p- 0.038); B: HIV positivity was not associated with Gender (p- 0.254).

\section{CONCLUSION}

Presence of molluscii was associated with HIV positivity with trunk, face, giant size and infection/ulceration, which can be a marker of HIV infection. Gender has no association with HIV infection. Thus, clinical presentation of Genital Molluscum differs with the HIV status of patients. Overall dissemination at multiple sites is common in HIV positive group.

\section{KEYWORDS}

Genital Molluscum, Comparison, Dissemination, Markers, HIV.

HOW TO CITE THIS ARTICLE: Balkrishna DS, Yoganand PJ, Pratap BS. Genital molluscum contagiosum and HIV- a comparative study. J. Evolution Med. Dent. Sci. 2017;6(40):3172-3174, DOI: 10.14260/Jemds/2017/685

\section{BACKGROUND}

We compare here clinical presentation of genital molluscum in HIV positive and negative group of patients. Molluscum Contagiosum (MC) or molluscii (i.e. plural of molluscum), occurs worldwide with a prevalence of $5 \%-11 \% .{ }^{1}$ By restriction endonuclease and PCR analysis of "molluscipox" DNA, mcv- 1 and 2 are common types, but MCV- 3 and 4 are rare types. Cellular transmission of viral DNA occurs above the suprabasal layer, forming a papule clinically and "molluscum body (Henderson-Paterson body)" an eosinophilic cytoplasmic inclusion of 25 micrometres on histological examination. Papules of MC can arise anywhere on the skin, but it can be accounted as a "Sexually Transmitted Disease, i.e. STD when it is contracted during a sexual contact from their sexual partner, usually on the genitalia having the risk of sexual transmission and autoinoculation. $^{2}$ So, GM being as a STD will have to be compared clinically in HIV status.

\section{MATERIALS AND METHODS}

\section{Aims and Objectives}

To compare clinically Genital Molluscum in HIV positive and negative group of 25 patients in each group.

Financial or Other, Competing Interest: None.

Submission 11-04-2017, Peer Review 05-05-2017,

Acceptance 11-05-2017, Published 18-05-2017.

Corresponding Author:

Dr. Dhumale Shashikant Balkrishna,

\#4, Dwarkanath Complex, Aaptenagar,

Kalamba Ringroad, New Vashinaka,

Kolhapur-416012, Maharashtra, India.

E-mail: dhumaleshashikant@gmail.com

DOI: $10.14260 /$ jemds $/ 2017 / 685$

\section{Settings and Design}

This observational, prospective and comparative study was conducted over 2-year period from March 2015 to February 2017. Sample size was decided as per our convenience by following the exclusion criteria like- 1 . Under-treatment patients, 2. Refusal to HIV test, 3. Refusal for pre- and/or post-test counselling, 4. Refusal for photographs, 5. Unwillingness for regular followup and treatment, 6. Refusal for the detection of other concomitant STDs. All these exclusions led to the sample size 25 in each group. The study was approved by the Institutional Ethics Committee (IEC) of the Hospital. Patients attending the Dermatology Outpatient (OPD) with complaints of lesion, having papule on genital and near the genitalia were examined. Inclusion criteria were patients of either gender between 15 - 60 years, willing to undergo HIV testing and photographs may be published. Simple consecutive sampling of MC patients 25 in each group of HIV positive and negative was done. Those patients having molluscii only on skin other than on genitals were excluded. Confidential interviews were undertaken to elicit risk factors like history of sexual contact with sex-partner, after which the lesion appeared. Suspected patients were screened for MC on genital as well as extragenital skin. Microscopic diagnosis of molluscum was done only in doubtful patients, by presence of intracytoplasmic eosinophilic hyaline inclusions (Henderson-Paterson body) using a Giemsa's stain. All patients were screened for HIV by HIV testing was done in the hospital laboratory, though patients who wished to get their HIV test by "ELISA" method done from other standard laboratories were allowed to do so. 


\section{Statistical Analysis}

Out of 50 patients, 28 patients are male and 22 patients are female. Data of age, gender, genital MC, face, trunk, giant size, infected/ulcerated MC are collected on each of these 50 patients. We have used statistical methods to analyse the above data. It includes "two samples proportion test" to count proportion between two HIV groups, nonparametric twosample Mann-Whitney test for comparing different quantitative characteristics of two groups (HIV positive and HIV negative), chi-square test for association of two qualitative characteristics. All the statistical analysis has been done using SPSS (16.0 version) software. Test results were considered significant at $\mathrm{p}<0.05$.

\section{RESULTS}

\begin{tabular}{|c|c|c|c|c|}
\hline \multicolumn{2}{|c|}{ Median } & \multicolumn{2}{c|}{ Interquartile Range } & P value \\
\cline { 1 - 4 } $\begin{array}{c}\text { HIV } \\
\text { Positive }\end{array}$ & $\begin{array}{c}\text { HIV } \\
\text { Negative }\end{array}$ & $\begin{array}{c}\text { HIV } \\
\text { Positive }\end{array}$ & $\begin{array}{c}\text { HIV } \\
\text { Negative }\end{array}$ & \multirow{2}{*}{0.000} \\
\cline { 1 - 4 } 43 & 28 & 11 & 14 & \\
\hline \multicolumn{3}{|c|}{ Tests: Mann-Whitney U -122.000 and 2-sided p-value- 0.000} \\
\hline \multicolumn{3}{|r|}{ Table 1. Age Wise Observations in Genital Molluscum } \\
\hline
\end{tabular}

Results of Table 1: In HIV positive mean age was 43 years, while mean age in negative patients was 28 years. By observing the p-value $<0.05$ (i.e. 0.000) there was a significant association of HIV positivity with age.

\begin{tabular}{|c|c|c|c|}
\hline \multirow{2}{*}{ Gender } & \multicolumn{2}{|c|}{ HIV Status } & \multirow{2}{*}{ Total } \\
\hline & HIV Negative & HIV Positive & \\
\hline Female & 9 & 13 & 22 \\
\hline Male & 16 & 12 & 28 \\
\hline Total & 25 & 25 & 50 \\
\hline
\end{tabular}

Test: Pearson Chi-Square- 1.299 df-1, 2-sided p-value- 0.254

Table 2. 2 × 2 Contingency Table for Gender and HIV Status

Results of Table 2: Male-to-female ratio was 1.27:1. By observing the p-value $>0.05$ (i.e. 0.254), gender and HIV status are not associated.

\begin{tabular}{|c|c|c|c|}
\hline Site & $\begin{array}{c}\text { Number of } \\
\text { HIV Positive } \\
\text { Patients }\end{array}$ & $\begin{array}{c}\text { Total Count } \\
\text { of HIV } \\
\text { Negative } \\
\text { Patients }\end{array}$ & P-value \\
\hline Molluscii on trunk & 15 & 2 & 0.006 \\
\hline Molluscii on face & 6 & 13 & 0.001 \\
\hline Giant size & 7 & 1 & 0.014 \\
\hline Infection/Ulceration & 9 & 3 & 0.038 \\
\hline
\end{tabular}

Test: Table 3: P values and associations of GM with HIV status in different parameters, Two samples Proportion test Table 3. Presence of Mollusci at various Sites in 2 Groups of $\mathrm{HIV}$

\section{DISCUSSION}

There is an increasing trend of viral STDs including molluscum contagiosum. ${ }^{3}$ As per study by Pujari Shital et al in 2015 in India, the incidence of MC in HIV infected persons rises from $5 \%-18 \%$ to $25 \%$ - 35\%. ${ }^{4}$ Larger lesions of more than $1 \mathrm{~cm}$ are called as "Giant molluscum." ${ }^{5}$ In the presence of HIV infection, the clinical appearance and the course of MC are atypical and clinical picture differs from the non-HIV population.

\section{Age}

In children, the typical distribution indicates that the transmission of the virus by occasional contact, which requires no HIV investigations. ${ }^{6}$ However, $\mathrm{MC}$ on genitalia in adult sexually active population will be an STD. ${ }^{7}$ As per Table
1, the mean age in HIV positive of MC was 43 years as compared to 28 years in negative, which shows a significant positivity as the age advances. In an Indian study, Narasimhalu and Muhilan in 2016 noted that those in age group 18 - 30 had the highest awareness (73.9\%), while age group above 40 years had the lowest awareness (46.7\%). ${ }^{8}$ This significant HIV positivity in MC patients above 40 age may be because of a loss of sexual spouse, alcoholism and better economic situation to afford sex with prostitutes, by which the risk of infection increases.

\section{Gender}

As per Table 2, though male were more than female, there was no significant relation with positivity $(\mathrm{P}>.05)$. In men, attitude of sex with poly-partners and unwanted sex makes them outnumbered than females. ${ }^{9}$ Comparatively, lower proportion of females can be explained on the grounds of diminished symptoms of STDs including genital MC in females may lead to failure to notice the disease and hence to report it. ${ }^{10}$

\section{Molluscum on Trunk}

In this study as per Table No. 3 , significant HIV positivity was found in molluscii on trunk. An intimate skin-to-skin contact is sufficient for transmission of the MC virus, which may be responsible for spread on trunk. ${ }^{11}$ Therefore, we recommend to rule out HIV infection for the spread of MC on trunk.

\section{Molluscum on Face}

HIV-infected patients may have lesions on trunk, but lesions on the face and neck are also common. ${ }^{12,13,14} \mathrm{MC}$ on the face, eyelid as in our study is consistent with previous studies as there was a significant association of number on face and in positivity our study as per Table 3. MC on the face should be investigated for immunosuppressive state.

\section{Giant Molluscum}

Though the MC is self-limiting and may clear spontaneously; however, in HIV infected persons they attain "Giant" size persists long and refractory to treatment. ${ }^{15}$ Ashok Kumar in India in 2015 noticed that giant MC is a clue to the diagnosis of HIV infection. ${ }^{16}$ Table 3 shows a significant positivity in HIV infection with "Giant" molluscum.

\section{Dissemination}

Takahiro Watanabe et al stated that the humoral immune response to MC virus is usually confined with MC and may be affected by the immunological condition of the host. ${ }^{17}$ The spread is on face including on eyelids, neck is common with CD4 count $<200$ cells $/ \mathrm{mm}^{4}$

\section{Infection or Ulceration}

As per Table 3, it was associated with HIV positivity. The bigger size molluscii are prone for infection or ulceration, usually found in HIV positive patients. As well as MC takes a chronic course and is usually refractory to various treatments in immune compromised patients, which is a foremost cause of above complications in HIV patients. ${ }^{15}$

\section{Dissemination}

Dissemination, i.e. spread at distant sites, away from genitalia with more numbers. From Table 3, it is more in HIV positive than negative group. There is a significant association with HIV positivity. The dissemination in HIV is very common and 
it spreads numerously at multiple sites than the seronegative group. Number may be inversely proportional to CD4 counts. ${ }^{18}$

Considerable debate remains as to whether the disease is caused by the reactivation of latent virus or whether it represents a recently acquired infection complicating the patient's progressive immunosuppression. Clinically, dissemination of MC in HIV-positive persons appears to be transmitted in both sexual and nonsexual patterns. ${ }^{12}$ Thus, disseminated atypical MC can be the first sign of HIV infection and AIDS. ${ }^{19}$

Both the spread and severity of disease or average number on all sites in this study increased in HIV positive patients of genital MC, which might have co-relation with advanced immunosuppression with low CD4 count, which could not be done in this study, for want of facilities and unaffordability. In an infection of HIV, Anti-Retroviral Treatment (ART) is recommended to reduce the risk of giant size, dissemination and autoinoculation as well as to increase patient's quality of life. ${ }^{20}$

\section{Limitations of Study}

The limited sample size is a reflection of the reduced prevalence of STIs in the general population. Our "exclusion" criteria of ongoing treatment, non-consent to HIV testing and non-consent to find other STDs also contributed to the limited sample size as mentioned in the beginning of the methodology. CD4 count could not be done because of the unaffordability, i.e. Cost factor.

\section{CONCLUSION}

The complications like dissemination, giant size, infection/ulceration are significantly associated more in HIV positive patients than sero-negative patients and can be a marker of HIV infection. HIV positivity was not associated with Gender. Clinical presentation of Genital Molluscum differs with the HIV status of patients. Overall, dissemination at multiple sites is common in HIV positive group.

\section{AKNOWLODGEMENT}

The Authors are thank full to the Bio-statistician, Mr. S.D. Pawar, (email-sdpawar23@gmail.com) Assistant Professor, Department of Biostatistics, Shivaji University, Kolhapur. (Maharasthra), India.

\section{REFERENCES}

[1] Jane CS. Viral infections. In: Christopher G, Jonathan B, (eds). Rook's textbook of dermatology. 9 th $^{\text {th }}$ edn. Chapter 25. Vol:1, UK: Wiley-Blackwell publication 2016:12-25.

[2] Tyring SK. Molluscum contagiosum: the importance of early diagnosis and treatment. Am J Obstet Gynecol 2003;189(3 Suppl):S12-6

[3] Shilpi S, Tiwari S, Vijay P, et al. Study of patterns of sexually transmitted diseases, using a syndromic approach in the era of human immunodeficiency virus from a tertiary care hospital of the Northern India. Indian J Sex Transm Dis 2015;36(2):158-61.

[4] Poojary SA, Kokane PT. Giant molluscum contagiosum with granulomatous inflammation and panniculitis: an unusual clinical and histopathological pattern in an HIV seropositive child. Indian J Sex Transm Dis 2015;36(1):95-8.
[5] Pérez-Díaz CE, Botero-García CA, Rodríguez MC, et al. Giant molluscum contagiosum in an HIV positive patient. Int J Infect Dis 2015;38:153-5.

[6] Gur I. The epidemiology of molluscum contagiosum in HIV-seropositive patients: a unique entity or insignificant finding? Int J STD AIDS 2008;19(8):503-6.

[7] Skerlev M, Husar K, Sirotković-Skerlev M. Mollusca contagiosa. From paediatric dermatology to sexually transmitted infection. Hautarzt 2009;60(6):472-6.

[8] Narasimhalu CRV, Muhilan J. Randomized questionnaire based cross-sectional research study on awareness of sexually transmitted diseases amongst the general population between those who completed their high school education and those who have not. Indian J Sex Transm Dis 2016;37(1):17-20.

[9] O'Sullivan LF, Hoffman S, Harrison A, et al. Men, multiple sexual partners, and young adults' sexual relationships: understanding the role of gender in the study of risk. J Urban Health 2006;83(4):695-708.

[10] CDC fact sheet-2011-women: CDC fact sheet: 10 ways STDs impact women differently from men. https://www.cdc.gov/std/health-disparities/stdswomen-042011.pdf.

[11] Stock I. Molluscum contagiosum--a common but poorly understood childhood disease and sexually transmitted illness. Med Monatsschr Pharm 2013;36(8):282-90.

[12] Bhanumathi N, Vishwanath BK. Extensive molluscum contagiosum in a HIV positive woman. Indian J Sex Transm Dis 2008;29(2):89-91.

[13] Massa AF, Borges-Costa J, Soares-Almeida L, et al. Molluscum contagiosum eyelid lesions in an HIVpatient. Dermatol Online J 2013;19(1):10.

[14] Kolokotronis A, Antoniades D, Katsoulidis E, et al. Facial and perioral molluscum contagiosum as a manifestation of HIV infection. Aust Dent J 2000;45(1):49-52.

[15] Vora RV, Pilani AP, Kota RK. Extensive giant molluscum contagiosum in a HIV positive patient. J Clin Diagn Res 2015;9(11):WD01-2.

[16] Sriparna B, Ashok K. Giant molluscum contagiosum - a clue to the diagnosis of human immunodeficiency virus infection. Journal of Epidemiology and Global Health 2013;3(4):289-91.

[17] Watanabe $T$, Nakamura $K$, Wakugawa $M$, et al. Antibodies to molluscum contagiosum virus in the general population and susceptible patients. Arch Dermatol 2000;136(12):1518-22.

[18] Schwartz JJ, Myskowski PL. Molluscum contagiosum in patients with human immunodeficiency virus infection: a review of twenty-seven patients. Journal of the American Academy of Dermatology 1992;27(4):583-8.

[19] Filo-Rogulska M, Pindycka-Piaszczyńska M, Januszewski K, et al. Disseminated atypical molluscum contagiosum as a presenting symptom of HIV infection. Postepy Dermatol Alergol 2013;30(1):56-8.

[20] Zichichi L, Maniscalco M. The challenges of a neglected STI: molluscum contagiosum. Ital Dermatol Venereol 2012;147(5):447-53. 